\title{
The Teaching and Learning Process of Mathematics in the Primary Education Stage: a Constructivist Proposal within the Framework of Key Competences
}

\author{
Luis Del Espino Díaz
}

University of Cordoba, SPAIN

ABSTRACT

This paper aims to analyze the importance of acquiring mathematical skills in the primary education stage within the framework of the key competences highlighting their contribution to the development of a mathematical culture of society, hence the importance of the issues addressed in this paper. After giving a description of what the competence approach entails in education, we will focus on the constructivist methodology applied to the area of mathematics to finalize with the elaboration of pedagogical guidelines that facilitate the teaching and learning process of mathematics in the stage of primary education.

teaching mathematics; constructivism; curriculum; mathematical competence; primary education
Received 15 May 2017

Revised 10 July 2017 Accepted 2 September 2017

\section{Introduction}

Mathematical science deals with describing and analyzing quantities, space and forms, changes and relationships, as well as uncertainty. It is a set of knowledge associated with numbers and forms that allow to know and structure reality, analyze it and obtain information to value it and make decisions, is identified with deduction, induction, estimation, approximation, probability, precision, rigor, safety.

Our daily life is surrounded by all these elements forming part of our culture and individuals must be able to appreciate and understand it. It not only contributes to a greater understanding of reality but also to the integral development of children.

\section{CORRESPONDENCE Luis Del Espino Díaz $\square$ luis.espino@uco.es}

๑) 2017 L. Del Espino Díaz.

Open Access terms of the Creative Commons Attribution 4.0 International License apply. The license permits unrestricted use, distribution, and reproduction in any medium, on the condition that users give exact credit to the original author(s) and the source, provide a link to the Creative Commons license, and indicate if they made any changes. (http://creativecommons.org/licenses/by/4.0/) 
Given the importance of the area of mathematics in primary education, we propose a pedagogical proposal based on constructivist theories focused on the acquisition of mathematical competence.

\section{The Mathematical Competence}

The mathematical and scientific literacy of citizenship has become a necessity of our society (Garmendia \& Guisasola, 2015). To do this, a series of strategies should be promoted from primary education to enable students to acquire skills and abilities in the area of scientific teaching so that they can be applied in any area of daily life that is necessary.

In this sense, we address the term of key competence applied to the educational field. The key competences are one of the fundamental aspects of the curricular approach of the education systems that is increasingly imposed in the most developed countries due to different actions carried out at international level such as the European Commission of Education (Piñero, Pulido and Falcon, 2017) based on the Delors Report (UNESCO, 1996). It is defined as the "knowhow" transferred to a diversity of academic, social and professional contexts. The competition integrates a series of factors such as practical skills and conceptual knowledge that, along with motivational, ethical and attitudinal elements and another of social nature are associated with the goal of effective action. Teaching by competences does not imply to change in the curricular elements of the subjects. It is rather a methodological change in which it is required that, in this particular case, the teacher of experimental and life sciences, acquires didactic strategies to implement this type of learning.

Specifically, we will focus on the mathematical competence that for the primary education stage must address the interest in the subjects' abilities to analyze and understand situations, identify applicable mathematical concepts and procedures, reason about them, generate solutions and express the results properly. Mathematical competence or mathematical literacy in primary education is defined as the individual's ability to identify and understand the role of mathematics in the world, to make sound judgments, to use mathematics and to engage with mathematics, and to meet the needs of mathematics. personal life as a constructive, committed and reflective citizen (Rico, 2007).

Alsina (2015) conducts a meta-analysis of the main contributions on the term of mathematical competence concluding that for the learning of mathematics it is necessary to strengthen the following aspects:

- Mathematical thinking: construction of mathematical knowledge based on meaningful experiences for students.

- Reasoning mathematically: carried out deductive and inductive processes.

- Raise and solve problems.

- Interpret and generate information with mathematical content.

- Correctly apply the use of training and communication technologies.

- Interpret and represent mathematical expressions, processes and results with words, drawings, symbols, numbers and materials.

- Communicate the results obtained using progressively mathematical language. 


\section{The Constructivist Approach Applied to the Area of Mathematics}

Constructivism is a learning theory that describes the process of knowledge construction. The construction of knowledge is an active process, not passive (Major \& Mangope, 2012). In the field of mathematics, this is because a mathematical learning based on constructivist theory provides the knowledge that is not only stored in the minds of students, but also actively building new knowledge from experience and knowledge. Effective learning of mathematics requires that students understand what they know and need to learn, and this motivation will help them learn more (Bhowmik, 2014, Jazim, Anwar \& Rahmawati, 2017). The most recognized authors within this stream of learning are Piaget, Ausubel. Vygotsky and Bruner whose principles can be summarized in (Diaz-Barriga and Hernández, 2002):

- Learning is an internal constructive process.

- The degree of learning depends on the level of cognitive development.

- The starting point for all learning is prior knowledge.

- Learning is a process of (re) construction of cultural knowledge.

- Learning is facilitated through mediation or interaction with others.

- Learning involves a process of internal reorganization of schemes.

- Learning occurs when what the student already knows with what he or she should know is in conflict.

For Guirles and Ramon (2002) the constructivist approach in the teaching and learning of mathematics is essential and establish what are the identifying elements of constructivism applied to mathematics. Next, we develop a proposal of work as pedagogical guidelines so that the implementation in the classroom of the constructivist approach can be carried out.

\section{Pedagogical Guidelines for the Application of the Constructivist Approach in the Mathematics Area}

In the line of Guirles and Ramon (2002) that establish a series of fundamental elements to take into account in the classroom of mathematics. These are: rationalization, adjustment and renewal of mathematical contents; mathematical literacy and numerical meaning; solve problems; globalization and mathematics for everyday life; the games. Then we move on to its development: With regard to the rationalization, adjustment and renewal of mathematical contents, the following considerations should be taken into account:

- Reduce the load of algorithms in the classroom.

- Strengthen mental calculation, approximation and scoring and prediction / estimation of results of all types of operations and mathematical problems.

- Encourage the introduction and continued use of the calculator from early childhood education and throughout primary education.

- To master the basic strategies of computation, using them in different contexts.

- Work the numbers and elementary operations in relation to the resolution of arithmetic problems and with their own contexts.

- Enhance spatial vision and geometric intuition versus formal and analytical geometry.

- Study the objects of everyday life. 
Develop mathematical literacy and numerical meaning. To do this, work in the classroom to focus on:

- Mathematical research, enabling the teaching-learning process to be significant through observation, experimentation and hypothesis formulation.

- Students should be the protagonists of their own learning; the teacher must perform a guidance function.

Problem solving is a key element in the approach we are proposing. In this sense, they empower autonomy and learn to learn, and they must allow an adequate educational treatment, attending to the different processes, rhythms and learning styles.

One of the objectives in proposing a constructivist methodology within the approach of the key competences is the fact of the transfer of the contents worked to the daily reality of the children and for this it is necessary a globalized approach of the mathematics for the daily life. Employing:

- The daily news of the media.

- Posing research situations in areas such as nature, sports and others.

With regard to games, they should be included in the teaching planning given that they work with:

- Memorization and numerical learning.

- The mental calculation.

- Problem solving.

\section{Conclusions}

As we have been reporting, one of the objectives of education systems is to ensure that children become competent people in the different fields of knowledge. In the specific case of mathematical competence, the teaching and learning process should be focused towards the assimilation of concepts, procedures and attitudes that make these curricular elements can be applied in real situations of daily life.

To this end, we propose a work plan in the classroom that responds to the constructivist positions of learning based on the principles of the development of intelligence in the realization of the cognitive functions of Piaget that considers intelligence as an extension of biological adaptation; the theory of meaningful learning created by Ausubel that develops from two basic axes: constructive activity and interaction with others (Romero, 2009); the work of Vygotsky (1998) that establishes the concept of Zone of Next Development as the distance in the real level of development; and Bruner's discovery learning in which the teacher presents the student with all the necessary tools for the student to discover for himself what he wants to learn (Baro, 2011).

\section{Disclosure statement}

The Authors reported that no competing financial interest.

\section{Notes on contributors}

Luis Del Espino Díaz, Professor of the Department of Education of the University of Cordoba. He holds a PhD in Education Sciences and a degree in 
Psychopedagogy from the University of Córdoba. He belongs to the research group "Education, Diversity and Society" of the Andalusian Plan of Research (Ref. SEJ-477) which includes among its lines of research stereotypes and prejudices in education, educational attention to diversity and intercultural education. He is a member of the Spanish Society of Pedagogy (SEP).

\section{References}

Alsina, Á. (2015). Cómo fomentar el aprendizaje de las matemáticas en el aula. Ideas clave para la Educación Primaria. Barcelona: Editorial Casals.

Baro, A. (2011). Metodologías activas y aprendizaje por descubrimiento. Revista Innovación y experiencias educativas. 40.

Bhowmik, M. (2015). Constructivism approach in mathematics teaching and assessment of mathematical understanding. Basic Research Journal of Education Research and Review, $4(1), 08-12$

Díaz-Barriga, F. y Hernández, G. (2002). Constructivismo y aprendizaje significativo. Mexico: Mc Graw Hill.

Garmendia Mujika, M., \& Guisasola Aranzabal, J. (2015). Alfabetización científica en contextos escolares: El Proyecto Zientzia Live!. Revista Eureka sobre Enseñanza y Divulgación de las Ciencias, 12(2).

Guirles, J. R. G., \& Ramón, J. (2002). El constructivismo y las matemáticas. Sigma: Revista de Matemáticas, Vitoria, (2), 113-129.

Jazim, Anwar, R.B. \& Rahmawati, D. (2017). The Use of Mathematical Module Based on Constructivism Approach as Media to Implant the Concept of Algebra Operation. IEJMEMathematics Education, 12(6), 579-583.

Major, T. E., Mangope, B. (2012). The Constructivist Theory in Mathematics: The Case of Botswana Primary Schools. International Review of Social Sciences and Humanities, 3(2) (2012), 139147

Martín, Y. (2013). Una propuesta constructivista, creativa y motivadora para el aprendizaje de las matemáticas en educación infantil. (Trabajo de Fin de Grado). UVA, Valladolid.

Piñero, M. A. C., Pulido, J. R., \& Falcón, J. A. A. (2017). El enfoque competencial educativo en el contexto europeo. El Guiniguada. Revista de investigaciones y experiencias en Ciencias de la Educación, 26, 62-76.

Rico, L. (2006). La competencia matemática en PISA. PNA, 1(2), 47-66.

Romero, F. (2009). Aprendizaje significativo y constructivismo. Revista digital Temas para la educación. 3

UNESCO (1996). La educación encierra un tesoro. Madrid: Editorial Santillana.

Vigotsky, L. (1988). El desarrollo de los procesos psicológicos superiores. México: Editorial Crítica, Grupo editorial Grijalbo. 